\title{
A LICITUDE DA GESTAÇÃO DE SUBSTITUIÇÃO NO BRASIL
}

\section{Amanda Souza Barbosa*}

\section{RESUMO}

Este trabalho tem como objetivo geral analisar a (i)licitude da gestação de substituição à luz do ordenamento jurídico brasileiro. Para tanto, foi adotado o método dialético e realizada pesquisa bibliográfica e documental. Tem-se como principal resultado a demonstração de que a gestação de substituição se coaduna com o sistema jurídico brasileiro, sobretudo com a dignidade humana e regime dos direitos da personalidade. A conclusão a que se chega é que, observados os requisitos da gratuidade e finalidade altruística, a prática pode ser considerada lícita.

Palavras-chave: gestação de substituição; licitude; dignidade humana; autonomia; direitos da personalidade.

\section{SURROGACY'S LEGALITY IN BRAZIL}

\begin{abstract}
This paper aims to analyze the surrogacy's legality or illegality according to the Brazilian legal system. To do so, the dialectical method has been adopted and a bibliographical and documentary research has been made. The main result is the demonstration that surrogacy is a practice in line with the Brazilian legal system, especially with human dignity and the personality rights regime. The conclusion reached is the surrogacy's legality if guaranteed it's gratuity and altruism.
\end{abstract}

Keywords: surrogacy; legality; human dignity; autonomy; personality rights.

\section{INTRODUÇÃO}

Dentre os principais avanços da biotecnologia no século XX estão as técnicas de reprodução humana assistida. Este conjunto de procedimentos que visa favorecer a fecundação humana passou a representar esperança para aqueles que não poderiam gerar uma criança pelas vias naturais, seja por ter sido acometido pela infertilidade, seja por haver algum impedimento de outra ordem, como é o caso das pessoas sozinhas e dos casais de pessoas do mesmo sexo.

\footnotetext{
* Doutoranda em Direito pela UFBA. Mestre em Direito pela UNISINOS. Especialista em Direito Médico (UCSAL) e Processo Civil (LFG). Professora de Direito Civil e Biodireito da UNIFACS. Pesquisadora nos grupos Vida (UFBA) e Clínica de Direitos Humanos (UFPR). Advogada. Endereço postal: Rua Manoel Gomes de Mendonça, n. 207, apt. 1602, Pituba, Salvador, Bahia, Brasil - CEP 41810-820. Endereço eletrônico: barbosa.asb@hotmail.com
} 
A gestação de substituição, objeto principal deste trabalho, compõe esse conjunto de técnicas. Consiste na gestação de um ser por parte de mulher não autora do projeto parental, ou seja, que contribui com o projeto parental alheio cedendo temporariamente seu útero para que o ser, concebido em laboratório, venha a ser gerado e se desenvolva até o nascimento. Tanto é assim que, como se verá, não há vínculo de filiação entre a criança e a cedente do útero.

Esta é uma realidade que ainda carece de regulamentação no Brasil por lei em sentido estrito, havendo apenas resolução do Conselho Federal de Medicina (CFM). A comercialização do procedimento e o turismo reprodutivo por ele provocado leva a reflexões sobre a adequação da prática e de que forma ela pode ser disponibilizada sem que a dignidade da pessoa humana seja violada. Por isso, tem-se como objetivo geral analisar a (i)licitude da gestação de substituição à luz do ordenamento jurídico brasileiro.

Para tanto, foi adotada a metodologia dialética e realizada pesquisa bibliográfica e documental. O desenvolvimento do presente artigo foi dividido em três momentos, cada um correspondente aos seguintes objetivos específicos: a) avaliar os riscos de reificação da pessoa humana; b) investigar a natureza jurídica da gestação de substituição; c) analisar a atual regulação da prática no Brasil pela Resolução CFM nº 2.168/2017. Com isto, pretende-se contribuir com a investigação da viabilidade ético-jurídica desta prática, para além de sua viabilidade técnica.

No primeiro item de desenvolvimento, identificou-se que a gestação de substituição remete à análise da possível reificação do ser humano. Sabe-se que a pessoa humana é dotada de dignidade, valor que lhe é inerente e que inviabiliza a sua instrumentalização. Gestar o(a) filho(a) de outrem, para alguns autores, fere esta condição. Por outro lado, há quem não observe tal impedimento e justifique a possibilidade da gestação de substituição enquanto decorrência do exercício dos direitos da personalidade, pressupondo-se a sua relativa disponibilidade.

Havendo, no Brasil, a realização dessa prática com base em resolução do CFM, é preciso perquirir a natureza desta relação jurídica. Este foi o objeto do segundo item de desenvolvimento do presente trabalho. A doutrina indica se tratar de uma relação jurídica contratual, havendo divergências sobre qual modalidade contratual lhe seria correspondente. Discutiu-se, também, a eventual ilicitude de seu objeto, na medida em que partes do corpo são bens jurídicos fora do comércio. Foram feitas considerações, ainda, sobre o exercício da autonomia neste âmbito. 
Ao final do desenvolvimento, em seu terceiro item, foi apresentada a regulação da gestação de substituição presente na Resolução CFM n 2.168/2017. Trata-se da quinta norma editada pelo Conselho, permanecendo o Estado brasileiro num limbo normativo. Observou-se que a prática é admitida, desde que observada a gratuidade e vínculo de parentesco entre a cedente do útero e os beneficiários, devendo outras circunstâncias serem apreciadas pelo CFM. Sob esses contornos, ao final, foram tecidas considerações sobre a (i)licitude da gestação de substituição no Brasil.

\section{CORPO HUMANO E MERCADO: OS RISCOS DE REIFICAÇÃO DO SER HUMANO}

Os avanços da biotecnologia, sobretudo a partir do século XX, tornou o homem objeto de si mesmo. A possibilidade de coisificação ou reificação do ser humano, colocando em xeque toda a construção em torno do valor da dignidade da pessoa humana, gerou preocupações em diversos estudiosos. Habermas (2004, p. 33-34), por exemplo, aponta para os riscos da chamada "tecnicização da natureza humana". A ciência, ao tornar cada vez mais disponível o ambiente natural, requer que se tornem normativamente indisponíveis as práticas tecnicamente viáveis, mas que representam um risco.

Em linha semelhante, a partir das lições de Savatier, Dias (1996, p. 142) aponta que não deve ser a "biologia a conduzir os destinos do direito mas é antes este que deverá regular a utilização daquela”. Portanto, resta assentada a premissa de que a mera disponibilidade técnica de um procedimento não o torna, necessariamente, lícito. Por isso, a despeito de praticada no Brasil e contar com regulação no âmbito do CFM, a gestação de substituição merece ser objeto de análise pormenorizada quanto à sua compatibilidade com o ordenamento jurídico pátrio.

Desde a primeira fecundação in vitro, que resultou no nascimento da inglesa Louise Brown em 1978, as técnicas de reprodução humana assistida têm sido alargadas e aperfeiçoadas. Na Inglaterra, o surgimento de agências comerciais que fomentam acordos de gestação de substituição deu azo à criação do Surrogacy Arrangements Act de 1985, o qual criminaliza aquele que viabiliza a negociação dos contratos de "aluguel de ventre" com finalidade comercial, bem como que divulga anúncios a respeito (DIAS, 1996, p. 88).

O Relatório Warnock, publicado em 1984, mostrou-se relutante a respeito. Dias (1996, p. 87) aponta que a maioria dos membros da comissão negou caráter vinculante a este 
tipo de acordo, sugerindo a responsabilização criminal de qualquer organização, pessoa ou profissional envolvido. Por outro lado, parte minoritária defendeu que a gestação de substituição fosse autorizada por uma entidade especificamente credenciada, viabilizada por instituição sem fins lucrativos e apenas quando for a única forma de realizar o projeto parental.

$\mathrm{Na}$ Espanha, a gestação de substituição é proibida na Ley de Técnicas de reproduccion asistida (1988). Essa é a tendência a nível do Conselho da Europa que chegou a não admitir, sequer, a maternidade de substituição por motivos filantrópicos. Gratuitos ou onerosos, tais contratos são considerados absolutamente nulos por terem um objeto contrário à lei e aos bons costumes. Seu objeto recairia sobre realidades fora do comércio, como a maternidade e a filiação (DIAS, 1996, p. 93-94).

Na base desta linha restritiva de tutela da gestação de substituição está a preocupação com a especialidade dos elementos envolvidos, que não podem ser meramente tratados como órgãos ou coisas. Tal prática gera reflexos diretos na esfera da integridade e intimidade da pessoa humana (DIAS, 1996, p. 132). A análise quanto à licitude da gestação de substituição pressupõe, portanto, seu confronto com as noções de dignidade da pessoa humana e direitos da personalidade - sobretudo o direito à integridade psicofísica.

$\mathrm{Na}$ linha da moral kantiana, a dignidade corresponde ao valor absoluto inerente a todo ser racional capaz de orientar a sua vontade segundo lei formulada por si e para si. A autonomia, portanto, é o fundamento da dignidade humana. A ela se contrapõe a heteronomia, a saber, as determinações externas da ação - a exemplo de necessidades e desejos. Agir moralmente seria sinônimo de agir com autonomia, de modo que as ações sejam compatíveis com uma lei universalizável (KANT, 1990, p. 92).

Inspirado nestas premissas, Barretto (2013, p. 75) aponta que o conteúdo da dignidade humana pode ser traduzido em duas máximas: "não tratar a pessoa humana como simples meio e assegurar as necessidades vitais da pessoa humana". Da primeira, extrai-se impedimento à reificação do ser humano, ao seu tratamento como peças destacáveis ou materiais biológicos. A segunda implica em seu tratamento como conjunção de corpo e espírito, cujas necessidades básicas devem ser atendidas para que não haja sujeição e degradação.

A dignidade humana figura como núcleo do ordenamento jurídico brasileiro, da promoção dos direitos fundamentais e dos direitos da personalidade (CANTALI, 2009, p. 53). Estes últimos podem ser conceituados como "direitos subjetivos que tem por objeto os bens e 
valores essenciais da pessoa, no seu aspecto físico, moral e intelectual” (AMARAL, 2006, p. 247). O bem jurídico "personalidade", portanto, se relaciona com a titularidade de direitos e deveres considerados inerentes a qualquer ser humano.

Embora ainda haja controvérsias no âmbito doutrinário, prevalece o entendimento de que, no Brasil, há um direito geral de personalidade fundado na dignidade humana, que não exclui os chamados direitos especiais de personalidade (PAGANINI, 2011, p. 13-14). O direito geral referido exerceria duas funções: a) os direitos especiais são corolários das projeções da personalidade jurídica, embora não esgotem a sua tutela; b) função integradora, suprimindo as lacunas porventura não tuteladas pelos direitos especiais (DIAS, 1996, p. 136137).

No Brasil, a despeito de ser o direito à integridade física um direito típico no $\mathrm{CC}$, não há dispositivo tutelando o fenômeno sob análise. Há quem diga que, se não há expressa vedação pelo direito, uma dada conduta seria lícita sem quaisquer limitações. Essa conclusão deriva da premissa de que o ser humano dispõe de si e de suas faculdades licitamente, sendo este poder a base de todo direito autêntico que, por conseguinte, dispensa o seu reconhecimento pelo direito positivo (DIAS, 1996, p. 138).

Em suma, as disposições sobre o próprio corpo não previstas como ilícito penal ou civil devem ser percebidas enquanto expressão consequencial da existência de tal direito (DIAS, 1996, p. 138). É preciso dar um passo adiante na análise, perquirindo-se se os direitos da personalidade comportam algum grau de disponibilidade. A despeito de serem reiteradamente descritos como indisponíveis pela doutrina tradicional, Borges (2007, p. 121) observa uma ampliação da autonomia jurídica individual nesse campo.

Para a autora, deve-se repensar essa indisponibilidade a partir dos avanços científicos e das novas necessidades humanas, admitindo-se uma disponibilidade relativa dos direitos da personalidade, sem perder de vista os limites oriundos da Constituição, lei, ordem pública e dignidade humana (BORGES, 2007, p. 121). Também para Gogliano (2000, p. 112) é possível dispor dos direitos da personalidade, pois são prerrogativas conferidas à pessoa para que possa fruir e dispor dos atributos essenciais da sua própria personalidade.

A disposição do direito à integridade física pode representar um desdobramento da dignidade humana em sua dimensão positiva, como leciona Cantali (2009, p. 155-157). Para a autora, o poder de disposição se afigura como fundamental para o exercício pleno de qualquer situação jurídica existencial, não sendo exclusivo do proprietário - esfera do ter, mas também 
estando ao alcance da pessoa na esfera do ser, em direção ao pleno desenvolvimento de sua personalidade:

\begin{abstract}
Ademais, a dignidade da pessoa humana, dentre outras dimensões, como já se suscitou antes, possui uma dimensão dúplice, negativa e prestacional. A dimensão negativa se manifesta como a necessidade de proteção da dignidade humana, tanto por parte do Estado como por parte dos particulares em sociedade, especialmente quando fragilizada, ameaçada de lesão ou até mesmo ofendida. Já a dimensão prestacional se manifesta no direito à autodeterminação pessoal, em função da qual se garante à pessoa a tomada de decisões a respeito de sua própria existência (CANTALI, 2009, p. 155).
\end{abstract}

Poder-se-ia apontar, ainda, que a admissão expressa da doação de órgãos e tecidos (art. 13, parágrafo único do CC e Lei $\mathrm{n}^{\circ}$ 9.434/1997) reflete uma certa disponibilidade do corpo humano. Em sentido contrário, Dias (1996, p. 141-143) afirma que o homem não é detentor de um autêntico direito subjetivo sobre o seu corpo, carecendo de poderes para dispor sobre os bens da personalidade, bens estes fora do comércio por excelência. Ademais, a gestação de substituição representaria ataque à ordem pública e aos bons costumes.

Vozes contrárias, a exemplo de Lojacono, não vislumbram contrariedade entre o referido procedimento e os marcos da ordem pública e bons costumes. Além de não provocar mal às partes envolvidas, as técnicas de reprodução humana assistida em geral permitem que pessoas realizem seu projeto parental a despeito de, por razões fisiológicas, terem sido privadas de fazê-lo pelas vias naturais (DIAS, 1996, p. 151). Sua finalidade, numa linha de raciocínio aparentemente assentada em raízes aristotélicas, seria determinante para sua admissão.

Outro ponto a se destacar é a imprecisão dos bons costumes enquanto marco interpretativo no Direito. Os valores sociais e culturais têm passado por nítidas transformações, além de ser a pluralidade moral uma marca das sociedades pós-modernas (HALL, 2005, p. 7-9). Qualquer decisão tomada sob essa premissa, necessariamente, estará privilegiando um determinado sistema moral ou ético cuja legitimidade pode não encontrar guarida social (BARBAS, 2006, p. 157). Ainda assim, situações problemáticas são apresentadas para análise.

Por volta da década de 1980, em duas oportunidades $-A$. v. C. (1978) e Re $P$. (Minors) v. Wardships (1987) - os tribunais britânicos enfrentaram casos em que a "mãe gestacional" não efetuou a entrega da criança após o nascimento. Em ambos os casos, firmouse o entendimento de que a recusa é legítima, na medida em que o estado de mãe não poderia 
ser renunciado. Ao entendimento contrário chegou o Tribunal de New Jersey ${ }^{l}$, nos Estados Unidos, ao considerar válido o contrato inicial, devendo ele ser cumprido (DIAS, 1996, p. 8789).

Para além das circunstâncias de recusa de entrega e da extensão da disponibilidade relativa dos direitos da personalidade, outros cenários verdadeiramente dramáticos podem se apresentar. Cite-se, por exemplo, circunstância em que a criança nasce com graves malformações e é rejeitada tanto pela cedente do útero quanto pelos autores do projeto parental (DIAS, 1996, p. 91), ou ainda a demanda por seu abortamento após dissolução da união entre os autores do projeto parental (BARBAS, 2006, p. 154).

\section{CONSIDERAÇÕES SOBRE A NATUREZA JURÍDICA DA GESTAÇÃO DE SUBSTITUIÇÃO}

Inegavelmente, a gestação de substituição está assentada na manifestação de vontade de uma mulher que aceita gestar o(a) filho(a) de outrem. Tal contexto faz surgir dúvidas a respeito da natureza jurídica deste ato. Nas palavras de Barbas (2006, p. 144): "Por mãe portadora entende-se a mulher que se obriga por contrato a suportar a gravidez por conta de outrem e a entregar a criança depois do parto". Haveria, portanto, uma relação jurídica contratual entre os autores do projeto parental e a cedente temporária do útero.

O contrato é modalidade de negócio jurídico por excelência, fazendo recair sobre si toda a tutela jurídica referente aos elementos de validade do segundo. Além das divergências em torno da natureza contratual, não há unanimidade sobre qual espécie contratual seria mais fiel aos contornos do quanto pactuado em sede de gestação de substituição. Entende-se que qualquer modalidade onerosa e cujo objeto recaia sobre uma coisa - compra e venda, locação etc. - não deve ser tida como premissa, sob pena de reificação do ser humano (AGUIAR, 2005, p. 109).

Daí se extrai, inclusive, a inadequação do termo "mãe de aluguel" para referência à mulher que cede temporariamente o seu útero. Também a prestação de serviço e empréstimo são relações contratuais pautadas na onerosidade, devendo ser afastadas. No contrato de

\footnotetext{
${ }^{1} \mathrm{O}$ famoso "Caso do Bebê M" se refere a episódio semelhante, em que a mãe substituta decidiu não efetuar a entrega da criança aos autores do projeto parental. Mesmo havendo vínculo biológico entre a criança e a mãe substituta, concluiu-se pela validade do contrato e entrega da criança ao casal contratante (AGUIAR, 2005 , p. 116).
} 
doação, a despeito da sua gratuidade, tem-se que o ato de liberalidade recai sobre bens ou vantagens de natureza patrimonial. Por isso, entende-se que se trata de modalidade sui generis e atípica (AGUIAR, 2005, p. 112).

Não havendo contrato típico no ordenamento jurídico brasileiro que reflita com fidelidade as suas características, adentra-se o campo da atipicidade contratual. Uma das grandes questões a respeito da gestação de substituição, uma vez apontada a sua natureza, é identificar se tal negócio seria válido (BARBAS, 2006, p. 146). Viu-se, no item anterior, que autores apontam a nulidade dessa prática por envolver bens fora do comércio, reificando o ser humano e violando a sua dignidade.

São elementos essenciais do negócio jurídico, de acordo com o art. 104 do CC: agente capaz; objeto lícito, possível e determinável; e forma prescrita ou não defesa em lei. Será considerado lícito o objeto não vedado por lei (LIMA, 2009, p. 464-465). In casu, não há lei em sentido estrito vedando a gestação de substituição. Há, apenas, resolução do CFM que regula a realização desse procedimento, editada diante deste vácuo jurídico-legislativo. Porém, isto não impede a análise de sua (in)compatibilidade com o ordenamento jurídico pátrio.

A questão reside em saber se a mulher pode dispor de sua integridade física nestes termos, sem que isto implique numa afronta à dignidade da pessoa humana. A própria noção de dignidade humana tem forte amparo na ética moral kantiana, segundo a qual nenhum ser humano pode ser tratado apenas como meio, mas sempre como um fim em si mesmo. Não seria dada a ninguém a possibilidade de dispor da humanidade, ainda que a ação recaia sobre si (BARRETTO; BRAGATO, 2013, p. 254-255).

Por outro lado, há quem entenda ser essa prática possível e ainda justifique o viés remuneratório. Em estudo sobre a temática, Barbas (2006, p. 146-148) sistematizou os argumentos nesse sentido. A autora explica que, para alguns, é inaceitável que uma família não ofereça nada em troca à cedente do útero, peça fundamental para execução do seu projeto parental. Além disso, tais contratos devem ter valor legal pela inexistência de lei que o proíba, ficando as partes adstritas ao seu cumprimento fiel e integral.

Contudo, acredita-se que o caráter remuneratório instrumentaliza as "mães portadoras", reduzindo o seu ato a mera contraprestação. A especialidade do objeto desta relação jurídica exige uma série de cautelas, no intuito de ser salvaguardada a dignidade humana da cedente do útero e, também, da criança. Em âmbito europeu, prevaleceu a proibição desta prática por esta razão, vide as recomendações para a sua proibição no relatório 
BENDA, no $88^{\circ}$ Congresso dos Médicos Alemães e Comissão Warnock (BARBAS, 2006, p. 150).

O Parlamento Europeu, em Resolução sobre Fecundação Artificial in vitro, rejeitou qualquer forma de maternidade por substituição. De acordo com o documento, devem ser penalizados os responsáveis pela mediação comercial com as mães hospedeiras, sendo proibido o funcionamento de empresas que exerçam tal atividade. Tais vedações se fazem presentes em países como a Espanha e Alemanha (BARBAS, 2006, p. 154). Portugal, por muito tempo, vedou a gestação de substituição, entendimento este alterado recentemente.

Em terras lusitanas, por meio de lei promulgada em 2016, passa a ser permitida a gestação de substituição, qualificada como negócio jurídico, observados determinados critérios. Dentre eles, diz-se expressamente que a gestante substituta deve entregar a criança após o parto, renunciando aos seus poderes decorrentes da maternidade, devendo um dos gametas ser, necessariamente, de um dos beneficiários. Além disso, são vedados o caráter comercial e a doação de material biológico pela cedente do útero (RETTORE; SÁ, 2016, p. $75)$.

O entendimento favorável à licitude da gestação de substituição parte da premissa de que o ato de ceder temporariamente o útero para a gestação de criança a ser entregue àqueles que manifestaram o desejo de concebê-la e tê-la como filha torna-se legítimo por meio do exercício da autonomia. Além disso, pode ser adicionado um argumento em prol da isonomia quanto à disponibilidade de meios técnicos a homens e mulheres que apresentem impossibilidade biológica de gerar um(a) filho(a):

\footnotetext{
Algo que parece ter escapado ainda à análise da maioria dos autores é o facto de a admissibilidade das mães de gestação poder ser um imperativo constitucional que decorra do princípio da igualdade. Ou seja, se se admite a inseminação heteróloga, em casos em que o homem tem problemas de infertilidade, não será de admitir o 'contrato de aluguer' nos casos em que a dificuldade reprodutiva decorre da mulher? (NETO, 2004, p. 599)
}

A nulidade se impõe na perspectiva de Barbas (2006, p. 154-155), decorrente de seu objeto, que incide sobre realidades insuscetíveis de comercialização, como a maternidade e a filiação. Ainda que realizada a título gratuito, a gestação de substituição feriria a dignidade humana e os direitos de personalidade, sobretudo o direito à integridade psicofísica, pois representa a sua renúncia antecipada pela cedente temporária do útero. Não poderia, pelo exercício da autonomia privada, a cedente afastar tal tutela jurídica que lhe é protetiva.

Aqui, os direitos da personalidade operariam como proteção da pessoa a ataques provenientes da pessoa contra si própria (BARBAS, 2006, p. 157). Em âmbito normativo, diz 
o art. 13 do CC: "Salvo por exigência médica, é defeso o ato de disposição do próprio corpo, quando importar diminuição permanente da integridade física, ou contrariar os bons costumes" (BRASIL, 2002). Não se pode dizer que a gestação provocará diminuição permanente da integridade física da cedente, por outro lado, o requisito dos bons costumes gera controvérsias, como já se viu.

A partir do estudo da matéria, Aguiar (2005, p. 109) bem sistematiza as principais questões que giram em torno da (i)licitude da gestação de substituição à luz do ordenamento jurídico brasileiro:

Do ponto de vista do direito civil pátrio, contrato desse teor tem recebido inúmeros argumentos, tanto a favor como contra a sua validade. Os mais consistentes, e que são mais comuns entre os doutrinadores de uma corrente e de outra, podem ser assim resumidos: a) aos que se pronunciam contra, devido ao fato de que o pagamento pela gestação e consequente entrega do filho implica em coisificação da pessoa e viola a garantia de dignidade humana, constitucionalmente assegurada no art. $1^{\circ}, \mathrm{III}$; b) a doutrina contrária manifesta-se no sentido de que o pagamento não se dá pela entrega de um objeto - a criança - mas, por um serviço social - o aluguel do útero e a eventual doação de óvulo.

$\mathrm{Na}$ perspectiva da autora, o objeto desta relação jurídica não seria o "serviço" de gestação em si, mas sim o seu "produto", a saber, a criança gerada e posteriormente entregue aos autores do projeto parental. A impossibilidade de considerar o filho um bem útil, a serviço dos desejos e interesses de seus genitores, conduziria à conclusão de que a licitude da gestação de substituição não se sustenta. Ainda que não haja prestação pecuniária, se estaria incorrendo na reificação do ser humano (AGUIAR, 2005, p. 110-112).

A despeito das considerações quanto à nulidade da gestação de substituição, forte sobretudo na literatura portuguesa, filia-se ao entendimento de que se trata de manifestação da autonomia jurídica da pessoa, desde que observado o marco da gratuidade. De acordo com Borges (2007, p. 219-220), ainda que de forma indireta, esta prática sempre seria remunerada. Prestar auxílio material à gestante, como acompanhamento pré-natal, corresponderia a uma forma de remuneração indireta, ou ainda uma via de compensá-la por seu ato.

Ainda assim, tal prática não retiraria a validade deste negócio jurídico, pois o livre exercício da autonomia privada é elemento que denota não estar reduzida a cedente temporária do útero à condição de objeto ou meio exclusivo para a consecução de uma finalidade de terceiro. Tendo-se em vista não só a gratuidade, mas a exigência feita pelo CFM quanto ao grau de parentesco entre a cedente e autores do projeto parental, percebe-se um cenário que não pode ser reduzido ao de mera instrumentalização. 


\section{ATUALIDADES SOBRE A REGULAMENTAÇÃO DA GESTAÇÃO DE SUBSTITUIÇÃO NO BRASIL}

A parte VII da resolução do CFM em vigor é dedicada a esta modalidade de reprodução humana assistida. Em seu primeiro item, determina que "a cedente temporária do útero deve pertencer à família de um dos parceiros em parentesco consanguíneo até o quarto grau", estando os demais casos sujeitos à autorização do Conselho Regional de Medicina (CFM, 2017). Desde a resolução anterior, o enunciado indica qual parente corresponde a cada grau, restringindo-o à linha descendente de parentesco.

Portanto, na resolução anterior, somente poderiam ceder o útero as filhas, irmãs, sobrinhas e primas. A partir da resolução atual, aponta-se expressamente que parentes em linha ascendente de parentesco também podem gestar a criança pretendida, ou seja, mães, avós e tias passam a contar explicitamente no enunciado normativo. Podem haver circunstâncias em que a cedente do útero não tenha vínculo de parentesco com os autores do projeto parental, mas venha a ter a sua participação autorizada pelo Conselho Regional.

No parecer do CFM n 07/2006, restou consignado que: "A doação temporária do útero por pessoa não-parente até o $2^{\circ}$ grau obrigatoriamente não tem caráter comercial e pode ser permitida quando se observa que a motivação é claramente afetiva". No caso analisado, a candidata a cedente temporária do útero é referida como "prima por afinidade", sendo amiga da paciente de longa data. Referiu ser mãe de quatro filhos, considerando sua prole completa, não desejando ampliar sua descendência, tendo motivação exclusivamente afetiva (CFM, 2006).

A exigência de parentesco entre a cedente do útero e um dos autores do projeto parental visa reduzir as possibilidades de comercialização da prática, cujas implicações foram trabalhadas nos itens anteriores. Logo após a indicação deste requisito, o item 2 da parte VII da Resolução CFM n ${ }^{\circ}$ 2.168/2017 determina que: “A cessão temporária do útero não poderá ter caráter lucrativo ou comercial” (CFM, 2017). Também o item 1 da parte IV desta mesma resolução afasta o caráter comercial no tocante à doação de gametas e embriões.

Ainda no intuito de garantir que a prática da gestação de substituição se dê em conformidade com ordenamento jurídico brasileiro, o item 3 da parte da resolução ora sob análise elenca quais documentos e observações devem constar no prontuário da paciente. $\mathrm{O}$ primeiro deles é o termo de consentimento livre e esclarecido (TCLE), assinado pelos 
pacientes e cedente do útero, cujo conteúdo deve abordar aspectos biopsicossociais, os riscos envolvidos no ciclo gravídico-puerperal e aspectos legais da filiação (CFM, 2017).

Percebe-se que o dever de informar por parte da equipe das clínicas de reprodução assistida é qualificado, na medida em que não se restringe aos riscos físicos inerentes ao procedimento. Deve-se considerar, necessariamente, o estado psicológico de todos os envolvidos, bem como a confirmação de que todos estão cientes de que o vínculo de filiação se dará entre bebê e pacientes, e não com a cedente do útero. Trata-se de ponto que desafia a noção tradicional de filiação, exclusivamente biológica (CFM, 2017).

Nessa linha, o segundo documento requerido pela resolução consiste em "relatório médico com o perfil psicológico, atestando adequação clínica e emocional de todos os envolvidos" (CFM, 2017). Na resolução anterior, esse laudo deveria ser providenciado somente para a cedente do útero, com vistas à devida compreensão do procedimento e redução das possibilidades de recusa à entrega da criança para os autores do projeto parental. A partir de 2017, também os pacientes devem passar por exame psicológico.

A questão da filiação é tão importante que, além de estar presente no TCLE, também será objeto de "termo de compromisso entre o(s) paciente(s) e a cedente temporária do útero (que receberá o embrião em seu útero), estabelecendo claramente a questão da filiação da criança”. Como bem observa Barbas (2006, p. 145), as técnicas de reprodução humana assistida permitem que uma criança seja concebida com a contribuição de até seis pessoas diferentes. A filiação poderia ser explicada de uma maneira tridimensional:

Podemos hoje falar numa tridimensionalidade procriativa. Neste sentido, teríamos uma dimensão orgânica, física e simbólica. Na primeira incluiríamos o pai/mãe genéticos (dador de esperma/óvulo); na dimensão física a mãe/pai gestacional (mãe portadora e seu companheiro) e na simbólica o pai/mãe adoptivos (BARBAS, 2006, p. 145).

Tradicionalmente, considera-se mãe aquela que dá à luz. Em momento anterior ao desenvolvimento das técnicas de reprodução humana assistida, a maternidade era tida como certa. Contudo, o avanço da biotecnologia neste campo tornou dissociável as figuras da "mãe geradora" e da "mãe genética", tornando necessária a normativa previamente apresentada para estabelecimento adequado dos vínculos de filiação. Nessa linha, Aguiar (2005, p. 114) explicita que o parto deixou de ter um valor indiscutível na determinação da maternidade:

Admite-se, assim, solução diferenciada para o caso de enfrentar-se, ou não, conflito entre a simples maternidade gestante e a maternidade genética. Para a hipótese em que houve mera utilização do útero alheio, caso em que não há vínculo biológico entre a mãe portadora e o bebê, o parto não poderá ser utilizado como fato jurídico 
determinante da maternidade, que deverá ser atribuída à mulher que quis o filho e assentiu na inseminação. Para tanto, suficiente a prova de que o embrião foi formado com os gametas do casal.

O afastamento da maternidade pautada no critério do nascimento, neste contexto, deve se dar tendo sido a etapa de concepção realizada por meio de técnica heteróloga ou homóloga. Em outras palavras, ainda que tenha sido ou não utilizado material genético de doador(a) anônimo para se chegar a embriões em laboratório, o parto não será determinante na indicação da maternidade. O vínculo de filiação será com a autora do projeto parental, havendo ou não ligação genética com o novo ser gerado (AGUIAR, 2005, p. 115).

Além dos documentos já indicados, deverá haver compromisso, por parte dos autores do projeto parental, de garantir à "mãe que cederá temporariamente o útero" acesso a tratamento e acompanhamento médico por equipes multidisciplinares até o puerpério (CFM, 2017). Neste ponto, cabe apontar que a referência à cedente temporária do útero como "mãe" não é adequada pois, como já explicitado, o vínculo de filiação não se dará com quem gesta, mas sim com os autores do projeto parental.

Cumpre salientar, ainda, que o amparo conferido à cedente por parte dos pacientes no tocante ao tratamento e acompanhamento médico não configura uma contraprestação, de modo que resta mantido o caráter não comercial desse procedimento. Não há qualquer contradição com o marco da gratuidade, portanto. Não seria razoável esperar que a cedente temporária do útero arcasse com todos os custos inerentes ao acompanhamento de uma gestação, estando ela apenas colaborando para que o projeto parental de outrem se realize.

Há, ainda, dois requisitos exigidos pela Resolução CFM nº 2.168/2017 no âmbito da gestação de substituição. Mais uma vez, a questão da filiação é objeto de item próprio: "3.5 Compromisso do registro civil da criança pelos pacientes (pai, mãe ou pais genéticos), devendo esta documentação ser providenciada durante a gravidez" (CFM, 2017). É importante alinhar com a equipe médica previamente para que a declaração de nascido vivo seja emitida corretamente, pois é o documento a ser levado ao cartório para fins de registro de nascimento.

Por fim, caso a cedente temporária do útero seja casada ou viva em união estável, deve ser colhida a aprovação do cônjuge ou companheiro por escrito (CFM, 2017). Por um lado, esta norma poderia ser justificada pelas mudanças que uma gravidez pode provocar na vida conjugal. Por outro, há quem aponte uma indevida ingerência no exercício da autonomia corporal da mulher, que ficaria impedida de decidir por si só a respeito de algo que afeta exclusivamente o seu organismo.

\footnotetext{
Revista de Biodireito e Direito dos Animais | e-ISSN: 2525-9695 | Salvador | v. 4 | n. 1 | p. 84 - 100 | 
Espera-se que o Poder Legislativo brasileiro se debruce sobre a temática com seriedade, numa perspectiva conciliatória, como aquela apresentada por Berlinguer (2004, p. 36):

[...] as leis devem refletir e, em certa medida, orientar uma sociedade pluralista, que seja baseada no inseparável binômio liberdade/responsabilidade, e assim não podem estabelecer vínculos, que não apresentem um fundamento racional demonstrado, como a ideia de que a derivação genética direta de dois genitores legalmente unidos seja a única que pode dar felicidade aos filhos.

Nessa linha, passa-se a considerações a respeito da licitude da gestação de substituição à luz do ordenamento jurídico brasileiro, bem como a apontamentos que visam a superação das problemáticas suscitadas ao longo do trabalho. A gestação de substituição já é uma realidade e merece regulação legal, assim como os demais contextos em torno da reprodução humana assistida, para que a sociedade conte com amparo normativo seguro, estável e efetivamente democrático, pois fruto da atividade do Poder Legislativo.

\section{CONCLUSÕES}

Partindo-se da não coincidência entre disponibilidade técnica e disponibilidade éticajurídica de uma determinada prática, tem-se que ainda se apresenta como problema a questão da admissibilidade da gestação de substituição no Brasil. Embora a prática já seja realizada e conte com regulação no âmbito do CFM, entende-se que há um vácuo jurídico-normativo a ser preenchido. Para tanto, uma questão inicial se impõe: a da (i)licitude da gestação de substituição à luz do ordenamento jurídico brasileiro.

O argumento de que a ausência de vedação expressa em lei implica em licitude de uma dada conduta, embora seja máxima condizente com o Direito Privado, é reputada deveras simplista. É preciso ir além, analisando-se o tema a partir de uma leitura sistemática do ordenamento jurídico. O primeiro desafio é submeter a conduta sob análise às lentes da dignidade da pessoa humana. À primeira vista, a dignidade humana, aqui referida, sobretudo, como a vedação à reificação do ser humano, parece um obstáculo.

Ocorre que, em suas raízes fincadas na moral kantiana, está o exercício da autonomia. Portanto, vislumbra-se na dignidade humana não um limite à cessão temporária do útero, mas sim fundamento da sua legitimidade. A autodeterminação corporal, enquanto manifestação da dimensão positiva da dignidade humana, confere legitimidade ao ato de gerar o(a) filho(a) de 
outrem, circunstância que enseja a disponibilidade relativa do direito à integridade psicofísica da cedente.

Viu-se que os direitos da personalidade, em regra descritos como indisponíveis, passam a ser referidos como relativamente disponíveis por autores contemporâneos, os quais demonstram que a disponibilidade pode estar a serviço do livre desenvolvimento da personalidade. Vislumbra-se que a gestação de substituição se alinha a essa esfera, desde que o móvel da cedente temporária do útero seja exclusivamente altruístico. Se admitida contraprestação pelo ato, a constatação da reificação do ser humano se impõe.

Nos moldes como delineada pela Resolução $\mathrm{n}^{\circ}$ 2.168/2017 do CFM, a cessão temporária do útero deve ser necessariamente gratuita, devendo haver, em regra, vínculo de parentesco entre a cedente e um dos beneficiários, autores do projeto parental. Nesse marco, não se identifica uma indevida instrumentalização do ser humano. A cedente, no exercício de sua autonomia privada e movida por fins altruísticos, gesta o(a) filho(a) de outrem, contribuindo para que um projeto familiar se concretize.

Por isso, não há que se falar em perturbação da ordem pública. Essa conjuntura nada mais representa do que uma alternativa para o exercício do direito fundamental ao livre planejamento familiar, direito este cujo conteúdo ganha novos contornos à medida em que a técnica avança. Tampouco deve ser considerado um impeditivo legal a contrariedade aos bons costumes, com fulcro no art. 13 do CC. A própria noção de bons costumes é excessivamente subjetiva, tornando-se inadequada enquanto filtro hermenêutico-jurídico.

Uma vez demarcada a admissibilidade da gestação de substituição à luz da dignidade e direitos da personalidade, cabe referir se tratar de um contrato atípico, de caráter não patrimonial, cujo objeto reside na gestação de uma criança em benefício da realização do projeto familiar de outrem. A entrega da criança é mero exaurimento da avença, na medida em que a filiação é aqui estabelecida com os autores do projeto parental, independentemente da concepção ter se dado mediante técnica homóloga ou heteróloga.

Entende-se que, nesses moldes - asseguradas a gratuidade e a finalidade exclusivamente altruística da cedente, a gestação de substituição deve ser considerada prática lícita, pois fruto do exercício da autodeterminação corpórea que não incorre em instrumentalização do ser humano. Nesses termos, a prática sob análise é compatível com a dignidade humana, não representa instrumentalização do ser humano, tampouco contraria a ordem pública e bons costumes. Pelo contrário, é exercício legítimo do direito geral à personalidade de todos os envolvidos. 


\section{REFERÊNCIAS}

AGUIAR, Mônica. Direito à filiação e bioética. Rio de Janeiro: Forense, 2005.

AMARAL, Francisco. Direito civil - introdução. 6. ed. rev. atual. e aum. Rio de Janeiro: Renovar, 2006.

BARBAS, Stela Marcos de Almeida Neves. Direito ao património genético. Coimbra: Almedina, 2006.

BARRETTO, Vicente de Paulo; BRAGATO, Fernanda Frizzo. Leituras de filosofia do direito. Curitiba: Juruá, 2013.

Ofetiche dos direitos humanos e outro temas. 2. ed. rev. e ampl. Porto Alegre: Livraria do Advogado, 2013.

BERLINGUER, Giovanni. Bioética cotidiana. Tradução Lavínia Bozzo Aguilar Porciúncula. Brasília: Editora Universidade de Brasília, 2004.

BORGES, Roxana Cardoso Brasileiro. Direitos da personalidade e autonomia privada. 2. ed. rev. São Paulo: Saraiva, 2007.

CANTALI, Fernanda Borghetti. Direitos da personalidade: disponibilidade relativa, autonomia privada e dignidade humana. Porto Alegre: Livraria do Advogado, 2009.

BRASIL. Lei $n^{o}$ 10.406, de 10 de janeiro de 2002. Institui o Código Civil. Disponível em: < http://www.planalto.gov.br/ccivil03/leis/2002/110406.htm>. Acesso em: 20 mar. 2018.

CONSELHO FEDERAL DE MEDICINA. Resolução $n^{\circ}$ 2.168, de 10 de novembro de 2017. Adota as normas éticas para a utilização das técnicas de reprodução assistida - sempre em defesa do aperfeiçoamento das práticas e da observância aos princípios éticos e bioéticos que ajudam a trazer maior segurança e eficácia a tratamentos e procedimentos médicos -, tornando-se o dispositivo deontológico a ser seguido pelos médicos brasileiros e revogando a Resolução CFM nº 2.121, publicada no D.O.U. de 24 de setembro de 2015, Seção I, p. 117. Disponível em: <http://sbra.com.br/images/legislacao/Resoluo-CFM.pdf〉. Acesso em: 25 mar. 2018.

CONSELHO FEDERAL DE MEDICINA. Parecer $n^{\circ}$ 07, de 12 de maio de 2006. Disponível em: <https://sistemas.cfm.org.br/normas/visualizar/pareceres/BR/2006/7>. Acesso em: 25 mar. 2018.

DIAS, João Álvaro. Procriação assistida e responsabilidade médica. Coimbra: Coimbra Editora, 1996.

GOGLIANO, Daisy. Autonomia, bioética e direitos da personalidade. Revista de Direito Sanitário, São Paulo, v. 1, n. 1, p. 107-127, nov. 2000. Disponível em: <http://www.revista susp.sibi.usp.br/scielo.php?pid=S1516-41792000000100009\&script=sci_arttext $>$. Acesso em: 25 mar. 2018. 
HABERMAS, Jürgen. O futuro da natureza humana. Tradução Karina Jannini. São Paulo: Martins Fontes, 2004.

HALL, Stuart. A identidade cultural na pós-modernidade. 10. ed. Rio de Janeiro: DP\&A, 2005 .

KANT, Immanuel. Fundamentos da metafísica dos costumes. Tradução Lourival de Queiroz Henkel. Rio de Janeiro: Ediouro, 1990.

LIMA, Flávia Gomes Silveira. Teoria geral dos negócios jurídicos. In: FIUZA, César (Org.) Curso avançado de direito civil. Rio de janeiro: Forense, 2009.

NETO, Luísa. O direito fundamental à disposição sobre o próprio corpo: a relevância da vontade na configuração do seu regime. Coimbra: Editora Coimbra, 2004.

PAGANINI, Juliano Marcondes. A "dupla crise" do modelo regulatório dos direitos da personalidade. In: TEPEDINO, Gustavo; FACHIN, Luiz Edson. (Org.) Pensamento crítico do Direito Civil brasileiro. Curitiba: Juruá, 2011.

RETTORE, Anna Cristina de Carvalho; SÁ, Maria de Fátima Freire. A gestação de substituição no Brasil: normatividade avançada e possibilidade de aprimoramento. In: CASTRO, Cristina Veloso de; SILVA, Mônica Neves Aguiar da. (Org.) Biodireito e direitos dos animais I. Florianópolis: CONPEDI, 2016. Disponível em: <https://www.conpedi.org.br/publicacoes/ 02q8agmu/23fs7c16/43JYs6251Cg10Pu3.pdf >. Acesso em: 30 mar. 2018. 